\title{
A measurement of social support in epidemiological research: the social experiences checklist tested in a general population in The Netherlands
}

\author{
M A van Oostrom, M A R Tijhuis, J C J M de Haes, R Tempelaar, D Kromhout
}

Department of Chronic Disease and Environmental Epidemiology (CCM), National Institute of Public Health and Environmental Protection (RIVM), PO Box 1 3720 BA Bilthoven, The Netherlands M A van Oostrom M A R Tijhuis

Department of Medical Psychology, University of Amsterdam and

Department of Medical Design Making,

University of Leiden, The Netherlands

J C J M de Haes

Department of Health Sciences,

University of

Groningen,

The Netherlands

$\mathrm{R}$ Tempelaar

Division of Public Health Research,

National Institute of

National Institute
Public Health and

Environmental

Protection,

Bilthoven,

The Netherlands

D Kromhout

Correspondence to:

Dr M A R Tijhuis.

Accepted for publication April 1995

\begin{abstract}
Study objective - This study aimed to examine in a general population the psychometric qualities of an instrument designed to measure positive and negative social experiences that had been developed in a clinical setting.

Design - The Netherlands monitoring project on cardiovascular disease risk factors, a large scale population based study (comprising 36588 men and women aged 20 to 59 years) carried out in three Dutch towns (Amsterdam, Doetinchem, and Maastricht) offered the possibility of testing the strength of this instrument cross sectionally.

Measurements and main results - The social experiences checklist (SEC) which resulted from a research project on the quality of life of cancer patients was used. The independence of positive and negative experiences was confirmed. The reliability of both the positive and negative experiences dimension was good (Cronbach's alpha $=0.82$ and 0.72 respectively). In accordance with the results of a study on cancer patients, the theoretically derived four dimensions in the experience of social support did not seem to be independent. The validity of the SEC was confirmed by Pearson correlations with neuroticism and coping styles. Neuroticism seemed to be negatively correlated with positive social experiences and was positively correlated with negative social experiences. The coping style of seeking information and direct action was positively correlated with positive social experiences. Coping by withdrawal was negatively correlated with negative social experiences. Women and highly educated people seemed to have more positive and fewer negative social experiences than men and people with less education. Younger people had more positive social experiences than older people. The oldest group in the study, those aged 50 to 59 , reported fewer negative social experiences than any other age group. Conclusions - Similar results were found in a study of cancer patients. This underlines the usefulness of the instrument not only for cancer patients but also in survey research in a general population.
\end{abstract}

(f Epidemiol Community Health 1995;49:518-524)
Social support is implicated in the aetiology of, recovery, and death from both physical and mental disease. ${ }^{1-7}$ Social support is not only supposed to have an effect on adaptation after life events, but can also lead to a reduction of health problems because of more adequate handling of these problems. ${ }^{38-10}$ The study of relationships between social support and morbidity and mortality was initiated by the classic studies of Cassel, ${ }^{1112}$ Caplan, ${ }^{13}$ and Cobb. ${ }^{14}$

Mechanisms by which characteristics of the social network influence disease have remained largely unidentified in this research. Recently, Cohen $^{5}$ and Schwarzer and Leppin ${ }^{7}$ have proposed models on the relationships between social networks and health. These models start from the differentiation of types of social support. Other aspects of social networks, like measures of type, quantity, and structure of social contacts, are assumed to influence the perceived or received social support. Schwarzer and Leppin point to the distinction between "cognitive" (perceived) and "behavioural" (received) support. Cognitive support is supposed to influence morbidity and mortality in a direct way, whereas behavioural support is supposed to buffer the effects of stress on morbidity. Social support is supposed to prevent and influence the course of cardiovascular diseases in particular. ${ }^{15-17}$ In an attempt to test the direct effects of social support on cardiovascular diseases, we incorporated a checklist investigating positive and negative social experiences (social experiences checklist, SEC) to measure social support in The Netherlands monitoring project on cardiovascular disease risk factors. The aim of this project was to monitor major risk factors for cardiovascular diseases. The SEC was originally developed in a study on the quality of life of cancer patients. ${ }^{1819}$ In this article, we will describe the psychometric qualities of the social experiences checklist (SEC) in a large population based sample.

\section{Methods}

SAMPLE

The data originate from The Netherlands monitoring project on cardiovascular disease risk factors that was carried out between 1987 and 1991. Each year, random samples of men and women, aged 20 to 59 years, were invited to participate. Stratified samples (according to age and gender) were taken from the registries of the towns of Amsterdam, Doetinchem, and 
Maastricht. Each year, for each gender and age stratum, 400 persons were selected in Doetinchem and Maastricht. In Amsterdam 500 persons were selected per year (owing to the expected lower response).

In Amsterdam, Doetinchem, and Maastricht respectively in 1987-91, 25 421, 20195 , and 22739 persons were invited to participate. The response in Amsterdam was $45.2 \%$, in Doetinchem $61 \cdot 7 \%$, and in Maastricht $55 \cdot 8 \%$. In all towns the attendance rate for women was higher than for men. For men as well as for women the attendance rate for the youngest age group was the lowest. The overall response rate was $53.5 \%$.

\section{INSTRUMENTS}

All persons who were willing to participate in the study received a questionnaire to be filled in at home. The SEC was part of this questionnaire. The respondent was asked to take the questionnaire to the municipal health service office, where it was checked for completeness and consistency by a trained technician.

The checklist on social experiences was developed to study the (experienced) quality of social relations. It was not developed to measure the extent of the social network. The construction of the checklist was based on three important theoretical notions. First, the foundation of the construction was the view of Thoits ${ }^{20}$ that social support has to be understood as the amount by which the social needs of an individual are fulfilled by the interaction with others. Secondly, social support was considered to have different dimensions. The four dimensions distinguished by Van de Vliert and De Boer ${ }^{21}$ were adopted:

- Emotional support (information to state that the receiver is beloved, one feels sympathy for him or her);

- Affirmational support (information to state that one is respected and admired);

- Instrumental support (practical help to reach a purpose); and

- Presence (information to make the receiver believe he or she has social ties).

Thirdly, both positive and negative experiences were included in the SEC. There is a growing interest in these negative experiences. ${ }^{322-24}$ As Coyne et al ${ }^{25}$ stated, "We know now that the problems and burdens posed by social relationships may be more closely related to adaptational outcomes than to the support that is provided, and similarly, that the degree of upset that relationships cause can be more important than their helpfulness". Relationships can be a source of conflicts, feelings of guilt, shame, and frustration ("nonsupport"26-28) as well as sources of a more positive nature. Taken together, the SEC reflects experiences in social relations, which can be positive as well as negative and are related to the emotional, affirmational, instrumental, and presence dimensions of social interaction.

To measure social experiences in a large scale survey, an instrument was needed that covered the described types of experiences and was clear, short, and easy to fill in. To achieve this a checklist was developed, based on an instrument formulated by Revenson et al, ${ }^{29}$ in which eight items represented the positive social experiences during the last week, independent from the source of support. The checklist of Revenson et al ${ }^{29}$ covered three of the four mentioned dimensions. Tempelaar $e t$ $a l^{18}$ added two items referring to the affirmational dimension to this list. Two other items as used by Revenson $e t$ al $^{29}$ were omitted - one emotional item and one instrumental item. A checklist of eight items evolved, which measured social interactions and covered the desired four dimensions. Analogous to the positive items, eight negative items were formulated by Tempelaar et al, ${ }^{18}$ which were also related to the four dimensions mentioned above. The positive and negative items were put in random order to reduce the response set. This new list was called the social experiences checklist (SEC).

The instrument that assesses social experiences consists, as described above, of 16 items. Eight items correspond to positive and eight to negative experiences. The answers on those items are formulated on a four point, Likert-type, scale (appendix) with answering categories:

- Never (1);

- Sometimes (2);

- Regularly (3); and

- Often (4).

To ensure uniformity of the total questionnaire, experiences were referred to the last month instead of the last week. As social experiences are supposed to be an "individual difference variable", there seemed to be no objections to this.

To establish the validity of the SEC, two other scales from the questionnaire, on neuroticism and coping, were used. Other research suggests that neurotic people and people who cope with all kinds of problems by withdrawal experience their social environment more negatively than people who are less neurotic or people who cope with their problems by acceptance or rational action. ${ }^{193031}$ Neuroticism was measured by a shortened version developed by $\mathrm{Ormel}^{32}$ of the $\mathrm{N}$-scale of the Amsterdam biographical questionnaire. This scale was originally developed by Wilde on the basis of the Maudseley personality inventory of Eysenck. The items in this questionnaire measure neuroticism that manifests as psychoneurotic, psychosomatic, or functional complaints. Coping was measured by a list of 19 items developed by de Haes. ${ }^{33}$ De Haes identified five dimensions:

- Seeking information and direct action;

- Cognitive ways to relieve emotions;

- Running away from problems;

- Withdrawal and guilt, and

- Unspecified direct action.

In de Haes' research on quality of life of cancer patients, the fourth factor (on withdrawal and guilt) showed a low reliability, and she therefore decided to analyse the different items separately. These items concern: (1) eating, drinking, and taking medicines, (2) withdrawal from others, (3) blaming others, (4) blaming your- 


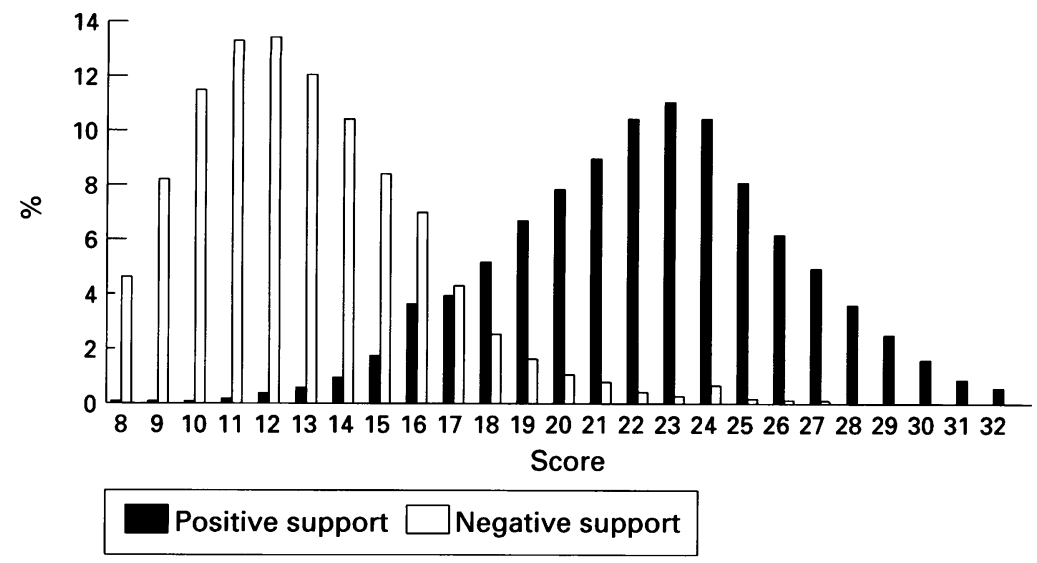

Social experiences scale - distribution of scores $(n=32$ 563).

\begin{tabular}{|c|c|}
\hline $\begin{array}{l}\text { Gender: } \\
\text { Male } \\
\text { Female }\end{array}$ & $\begin{array}{l}46 \cdot 9 \% \\
53 \cdot 1 \%\end{array}$ \\
\hline $\begin{array}{r}\text { Age (y): } \\
20-29 \\
30-39 \\
40-49 \\
50-59\end{array}$ & $\begin{array}{l}18 \cdot 7 \% \\
26 \cdot 4 \% \\
27.8 \% \\
27 \cdot 1 \%\end{array}$ \\
\hline $\begin{array}{l}\text { Educational } \\
\text { Low } \\
\text { Medium } \\
\text { High }\end{array}$ & $\begin{array}{l}44.9 \% \\
37 \cdot 0 \% \\
18 \cdot 2 \%\end{array}$ \\
\hline
\end{tabular}

self. If the factors distinguished by de Haes show low reliability in this study, we will also analyse the different items separately. Sociodemographic characteristics (gender, age, and education) of the sample are described in table 1. Age is grouped into four categories (20-29 years, 30-39 years, 40-49 years, and 50-59 years). Education refers to the highest completed type of education, which is coded in three categories: low (low secondary education or less), medium (vocational or higher secondary education), and high (higher vocational or university education).

\section{STATISTICS}

The psychometric qualities of the SEC were determined by the distribution of answers per item, the independence of positive and negative experiences, the independence of the four dimensions of support, and the reliability and validity of the instrument. Frequency distributions, means (SD) per item, were calculated to evaluate the distribution of answers. To determine the independence of negative and positive experiences, and the independence of the four dimensions of support, we performed principal component factor analyses with varimax rotation and calculated Pearson product-moment correlations. We performed a forced two factor analysis to distinguish negative from positive experiences, and a forced four factor analysis to distinguish the four different dimensions of support. We choose 0.25 as the lowest value of the factor loadings to be considered. The reliability of the checklist (and of the lists used for validation of the SEC) were determined by evaluating Cronbach's alphas. To determine the validity of the SEC, we calculated Pearson product-moment correlations with neuroticism and coping. To conclude, we calculated mean scale scores for men and women, for different age groups, and for different groups according to education. The differences between these groups were tested with the F-test, ANOVA. All statistical analyses are carried out using $S A S$, version 6.07. All tests were two tailed and a p value of 0.001 or lower was considered statistically significant. Due to different numbers of missing values on specific items of the SEC, the number of respondents included in the analysis differs per analysis.

\section{Results}

FREQUENCY DISTRIBUTIONS

The distribution of the answers on the items are presented in table 2 . The figure shows the distribution of the scale scores. A number of respondents did not fill in one or more items of the SEC. The item non-response for the group of positive items was $9 \cdot 1 \%$ and that for the group of negative items $9 \cdot 2 \%$. A total of $32563(89 \%)$ respondents answered all items referring to their social experiences.

The sum of the items measuring positive experiences is well distributed (skewness= $-0 \cdot 18$, kurtosis $=0.01$ ) with a minimal skewness to the left. The distribution of the sum of

Table 2 Frequency distribution (\%) of the items measuring social experiences $(n=36588)$

\begin{tabular}{|c|c|c|c|c|c|c|c|}
\hline Item description & $\begin{array}{l}\text { Score } 1 \\
\text { never }\end{array}$ & $\begin{array}{l}\text { Score } 2 \\
\text { sometimes }\end{array}$ & $\begin{array}{l}\text { Score } 3 \\
\text { regularly }\end{array}$ & $\begin{array}{l}\text { Score } 4 \\
\text { often }\end{array}$ & Mean & $(S D)$ & No \\
\hline $\begin{aligned} & \text { Positive items: } \\
& 1 \text { Warmth and friendliness } \\
& 3 \text { Esteem } \\
& 5 \text { That someone spent a pleasant time with you } \\
& 8 \text { Understanding and sympathy } \\
& 9 \text { Useful information or suggestions } \\
& 12 \text { The help of someone } \\
& 15 \text { That someone trusted you } \\
& 16 \text { That someone took time to be with you }\end{aligned}$ & $\begin{array}{r}0 \cdot 7 \\
2 \cdot 3 \\
3 \cdot 5 \\
2 \cdot 7 \\
7 \cdot 2 \\
11 \cdot 2 \\
1 \cdot 8 \\
4 \cdot 9\end{array}$ & $\begin{array}{l}16 \cdot 7 \\
37 \cdot 2 \\
23 \cdot 4 \\
27 \cdot 2 \\
47 \cdot 5 \\
49 \cdot 2 \\
18 \cdot 4 \\
27 \cdot 0\end{array}$ & $\begin{array}{l}51 \cdot 7 \\
49 \cdot 3 \\
49 \cdot 6 \\
55 \cdot 4 \\
38 \cdot 0 \\
32 \cdot 1 \\
54 \cdot 3 \\
46 \cdot 3\end{array}$ & $\begin{array}{r}30 \cdot 9 \\
11 \cdot 2 \\
23 \cdot 5 \\
14 \cdot 8 \\
7 \cdot 4 \\
7 \cdot 5 \\
25 \cdot 0 \\
21 \cdot 8\end{array}$ & $\begin{array}{l}3 \cdot 1 \\
2 \cdot 7 \\
2 \cdot 9 \\
2 \cdot 8 \\
2 \cdot 4 \\
2 \cdot 4 \\
3 \cdot 0 \\
2 \cdot 9\end{array}$ & $\begin{array}{l}(0 \cdot 70) \\
(0 \cdot 70) \\
(0 \cdot 78) \\
(0 \cdot 70) \\
(0 \cdot 73) \\
(0 \cdot 78) \\
(0 \cdot 71) \\
(0 \cdot 81)\end{array}$ & $\begin{array}{l}35060 \\
34524 \\
34397 \\
34325 \\
34158 \\
34371 \\
34403 \\
34354\end{array}$ \\
\hline $\begin{aligned} & \text { Negative items: } \\
& 2 \text { Incomprehension } \\
& 4 \text { That people were not willing to help you } \\
& 6 \text { That someone belittled you } \\
& 7 \text { That people did not give you enough information } \\
& 10 \text { Excessive concern } \\
& 11 \text { That someone avoided you } \\
& 13 \text { That someone did not take you seriously } \\
& 14 \text { That people did not leave you in peace }\end{aligned}$ & $\begin{array}{l}19 \cdot 8 \\
44 \cdot 3 \\
66 \cdot 7 \\
39 \cdot 8 \\
40 \cdot 4 \\
72 \cdot 5 \\
57 \cdot 1 \\
57 \cdot 3\end{array}$ & $\begin{array}{l}69 \cdot 6 \\
46 \cdot 5 \\
30 \cdot 1 \\
51 \cdot 1 \\
42 \cdot 7 \\
24 \cdot 1 \\
37 \cdot 8 \\
32 \cdot 0\end{array}$ & $\begin{array}{r}7 \cdot 7 \\
6 \cdot 4 \\
2 \cdot 0 \\
7 \cdot 0 \\
11 \cdot 2 \\
2 \cdot 1 \\
3 \cdot 6 \\
7 \cdot 7\end{array}$ & $\begin{array}{l}3 \cdot 0 \\
2 \cdot 9 \\
1 \cdot 2 \\
2 \cdot 1 \\
5 \cdot 6 \\
1 \cdot 2 \\
1 \cdot 5 \\
3 \cdot 0\end{array}$ & $\begin{array}{l}1.9 \\
1.7 \\
1.4 \\
1.7 \\
1.8 \\
1.3 \\
1.5 \\
1.6\end{array}$ & $\begin{array}{l}(0.62) \\
(0.72) \\
(0.59) \\
(0.69) \\
(0.84) \\
(0.58) \\
(0.64) \\
(0.76)\end{array}$ & $\begin{array}{ll}34 & 510 \\
34 & 384 \\
34 & 453 \\
34 & 306 \\
34 & 322 \\
34 & 258 \\
34 & 308 \\
34 & 246\end{array}$ \\
\hline
\end{tabular}


Table 3 Correlation matrix of the items of the social experiences checklist

\begin{tabular}{|c|c|c|c|c|c|c|c|c|c|c|c|c|c|c|c|c|}
\hline \multirow[t]{2}{*}{ Item } & \multicolumn{8}{|c|}{ Items on positive experiences } & \multicolumn{8}{|c|}{ Items on negative experiences } \\
\hline & 1 & 3 & 5 & 8 & 9 & 12 & 15 & 16 & 2 & 4 & 6 & 7 & 10 & 11 & 13 & 14 \\
\hline 3 & 0.43 & & & & & & & & & & & & & & & \\
\hline 5 & 0.47 & $0 \cdot 36$ & & & & & & & & & & & & & & \\
\hline 8 & 0.48 & 0.43 & 0.43 & & & & & & & & & & & & & \\
\hline 9 & 0.33 & $0 \cdot 32$ & $0 \cdot 31$ & 0.44 & & & & & & & & & & & & \\
\hline 12 & 0.29 & $0 \cdot 24$ & $0 \cdot 27$ & $0 \cdot 31$ & 0.35 & & & & & & & & & & & \\
\hline 15 & 0.35 & $0 \cdot 36$ & 0.37 & 0.39 & 0.29 & 0.26 & & & & & & & & & & \\
\hline 16 & 0.42 & $0 \cdot 34$ & 0.51 & 0.40 & $0 \cdot 31$ & 0.33 & 0.47 & & & & & & & & & \\
\hline 2 & $-0 \cdot 16$ & $-0 \cdot 13$ & $-0 \cdot 11$ & $-0 \cdot 14$ & -0.04 & $-0 \cdot 02$ & -0.06 & -0.09 & & & & & & & & \\
\hline 4 & $-0 \cdot 18$ & $-0 \cdot 14$ & $-0 \cdot 14$ & -0.15 & -0.07 & -0.03 & -0.07 & -0.13 & $0 \cdot 34$ & & & & & & & \\
\hline 6 & $-0 \cdot 18$ & $-0 \cdot 14$ & $-0 \cdot 14$ & $-0 \cdot 15$ & -0.05 & -0.03 & -0.09 & $-0 \cdot 10$ & 0.34 & $0 \cdot 31$ & & & & & & \\
\hline 7 & -0.15 & -0.13 & $-0 \cdot 10$ & -0.12 & -0.03 & -0.01 & -0.04 & $-0 \cdot 10$ & 0.32 & 0.34 & 0.33 & & & & & \\
\hline 10 & 0.05 & $0 \cdot 11$ & 0.08 & 0.09 & $0 \cdot 14$ & $0 \cdot 16$ & $0 \cdot 13$ & $0 \cdot 15$ & $0 \cdot 10$ & $0 \cdot 10$ & $0 \cdot 14$ & 0.09 & & & & \\
\hline 11 & $-0 \cdot 14$ & -0.08 & $-0 \cdot 11$ & -0.11 & -0.02 & 0.00 & -0.07 & -0.08 & 0.25 & 0.25 & 0.33 & $0 \cdot 26$ & $0 \cdot 14$ & & & \\
\hline 13 & -0.15 & -0.13 & $-0 \cdot 10$ & $-0 \cdot 14$ & -0.04 & 0.01 & -0.08 & -0.09 & 0.32 & 0.28 & 0.40 & 0.31 & 0.13 & 0.33 & & \\
\hline 14 & -0.07 & -0.04 & -0.04 & -0.05 & 0.03 & 0.04 & 0.04 & -0.02 & 0.25 & 0.25 & 0.27 & 0.25 & 0.15 & 0.26 & $0 \cdot 30$ & \\
\hline
\end{tabular}

Number ranges from 34158 to 35060 (pairwise deletion of missing values).

For $=34158, p<0.001$ for $r>0.02, p<0.01$ for $r>0.01$.

Average inter-item correlation for positive items $=0.37(\mathrm{n}=33241)$

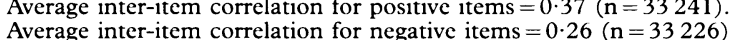

Average inter-item correlation between positive and negative items $=-0.06(\mathrm{n}=32563)$.

Table 4 Factor matrix after varimax-rotation $(n=$ 32 563)

\begin{tabular}{|c|c|c|}
\hline & Factor I & Factor II \\
\hline \multicolumn{3}{|c|}{ Items on positive experiences: } \\
\hline 1 & $0 \cdot 70$ & \\
\hline 3 & 0.64 & \\
\hline 5 & 0.69 & \\
\hline 8 & $0 \cdot 72$ & \\
\hline 9 & $0 \cdot 62$ & \\
\hline 12 & $0 \cdot 57$ & \\
\hline 15 & 0.66 & \\
\hline 16 & 0.71 & \\
\hline \multicolumn{3}{|c|}{ Items on negative experiences: } \\
\hline 2 & & $0 \cdot 62$ \\
\hline 4 & & $0 \cdot 60$ \\
\hline 6 & & 0.67 \\
\hline 7 & & $0 \cdot 62$ \\
\hline 10 & $0 \cdot 28$ & $0 \cdot 33$ \\
\hline 11 & & 0.59 \\
\hline 13 & & 0.66 \\
\hline 14 & & $0 \cdot 58$ \\
\hline
\end{tabular}

$\mathrm{R}^{2}$ total $=41 \cdot 2 \%$

Only factor loadings $>0 \cdot 25$ are shown

the items measuring the negative experiences is skewed to the right (skewness $=0.96$, kurtosis $=1 \cdot 60)$.

\section{INDEPENDENCE OF POSITIVE AND NEGATIVE EXPERIENCES}

Pearson correlations are shown in table 3. The average inter-item correlations of the positive items was $r=0.37$ and that of the negative items was $r=0 \cdot 26$. The average inter-item correlation between positive and negative items amounts

Table 5 Factor matrix after varimax rotation

\begin{tabular}{|c|c|c|c|c|}
\hline & Factor $I$ & Factor II & Factor III & Factor IV \\
\hline \multicolumn{5}{|c|}{ For items of positive experiences $(n=33241)^{*}$} \\
\hline Item 1 - emotional & 0.64 & $0 \cdot 50$ & & \\
\hline Item 3 - affirmational & & $0 \cdot 77$ & & $0 \cdot 28$ \\
\hline Item 5 - presence & $0 \cdot 83$ & & & \\
\hline Item 8 - emotional & $0 \cdot 36$ & $0 \cdot 64$ & & \\
\hline Item 9 - instrumental & & 0.56 & $0 \cdot 61$ & \\
\hline Item 12 - instrumental & & & $0 \cdot 87$ & \\
\hline Item 15 - affirmational & & $0 \cdot 27$ & & 0.88 \\
\hline Item 16 - presence & $0 \cdot 63$ & & & 0.53 \\
\hline \multicolumn{5}{|c|}{ For items of negative experiences ( $n=33226$ ) } \\
\hline Item 2 - affirmational & 0.64 & & $0 \cdot 26$ & \\
\hline Item 4 - instrumental & $0 \cdot 62$ & & $0 \cdot 46$ & \\
\hline Item 6 - instrumental & $0 \cdot 68$ & & & \\
\hline Item 7 - affirmational & 0.63 & & $0 \cdot 25$ & \\
\hline Item 10 - emotional & $0 \cdot 28$ & 0.90 & $0 \cdot 27$ & \\
\hline Item 11 - presence & 0.59 & & -0.49 & \\
\hline Item 13 - emotional & $0 \cdot 67$ & & $-0 \cdot 32$ & \\
\hline Item 14 - presence & $0 \cdot 57$ & & & $0 \cdot 80$ \\
\hline
\end{tabular}

${ }^{*} \mathrm{R}^{2}$ total $=73 \cdot 7 \%$. Only factor loadings $>0 \cdot 25$ are shown

$\mathrm{R}^{2}$ total $=67 \cdot 5 \%$. Only factor loadings $>0 \cdot 25$ are shown to $r=-0 \cdot 06$. The Pearson product-moment correlation between the positive and negative scale is small $(r=-0 \cdot 13)$.

The factor analyses to determine the independence of positive and negative experiences are reported in table 4 . The two factors have an Eigen value of more than $2 \cdot 5$. The loadings of the positive items on the first factor amount to 0.57 or more. The negative item 10 ("excessive concern") has a different position, because it has a loading of 0.28 or higher on both factors. The communality of this item is $0 \cdot 19$. The communalities of the other items fluctuate between 0.33 and 0.54 . If item 10 ("excessive concern") is removed from the group of negative items the average inter-item correlation for this group increases to $r=0 \cdot 30$. The negative items with the exception of item $10(0.33)$ have factor loadings of 0.58 and higher on the second factor. Of all items with a loading higher than $0 \cdot 25$, item 14 ("not to be left in peace") has the lowest value $(0 \cdot 58)$.

INDEPENDENCE OF THE FOUR DIMENSIONS

The factor analyses to determine the independence of the four dimensions of support are reported in table 5 . From this table, an unrecognisable pattern concerning the positive dimension becomes visible. Most items have a loading on more than one factor. The "emotional" items load on factors I and II, the "affirmational" items load on factors II and IV, "presence" item 16 loads on factors I and IV and the "instrumental" item 9 loads on factors II and III. In addition, the negative dimension does not show a clear structure. All items load on factor I and six of the eight items also load on factor III. The communalities of the positive items vary between 0.62 and 0.89 and that of the negative items between 0.51 and 1.00 . Since these four dimensions can not be distinguished properly, we limit further analyses presented here to the two scales of positive and negative social experiences.

\section{RELIABILITY}

The positive social experiences dimension shows a high degree of reliability (Cronbach's 
Table 6 Correlations between the social experiences checklist, neuroticism, and coping

\begin{tabular}{lcc}
\hline & \multicolumn{2}{c}{ Social experiences checklist } \\
\cline { 2 - 3 } & Positive & Negative \\
\hline Neuroticism & $0 \cdot 27$ & -0.45 \\
Coping: & $0 \cdot 40$ & 0.04 \\
Seeking information and direct action & $0 \cdot 11$ & $0 \cdot 03$ \\
Cognitive ways to relieve emotions & $0 \cdot 07$ & $0 \cdot 08$ \\
Running away from problems & $-0 \cdot 14$ & $0 \cdot 37$ \\
Withdrawal and guilt & $-0 \cdot 07$ & $0 \cdot 22$ \\
Eating, drinking and taking medicines & $-0 \cdot 17$ & $0 \cdot 28$ \\
Withdrawal from others & $-0 \cdot 07$ & $0 \cdot 24$ \\
Blaming others & $-0 \cdot 04$ & $0 \cdot 20$ \\
Blaming yourself & $0 \cdot 10$ & $0 \cdot 17$ \\
Unspecified direct action & $-0 \cdot 01$ & $0 \cdot 19$ \\
Do something, whatever & $0 \cdot 16$ & $0 \cdot 08$ \\
Do something that helped before & &
\end{tabular}

The number ranges from 32320 to 34129 .

All correlations are statistically significant, $\mathrm{p}<0 \cdot 001$.

$\alpha=0 \cdot 82$ ). The negative social experiences dimension is less reliable $(\alpha=0.72)$ than the dimension of positive social experiences. When item 10 ("excessive concern") is removed the Cronbach's alpha increases to $0 \cdot 74$.

\section{VALIDITY}

Pearson correlations between neuroticism, types of coping, some items on coping (the items of factors 4 and 5, which have low reliability), and the SEC are shown in table 6. The reliability of the scale on neuroticism in this study is $\alpha=0 \cdot 83$. Correlations ( $p<0.001$ ) between neuroticism and positive social experiences $(r=-0 \cdot 27)$ and between neuroticism and negative social experiences $(r=0.45)$ are as expected. The reliability of the types of coping are $\alpha=0.74$ for seeking information and direct action, $\alpha=0.68$ for cognitive ways to relieve emotions, $\alpha=0.69$ for running away from problems, $\alpha=0.51$ for withdrawal and guilt, and $\alpha=0.36$ for unspecified direct action. The strongest positive correlation is found for the combination of positive social experiences and seeking information and direct action $(r=$ $0 \cdot 40$ ). The strongest negative correlation is found for the combination of withdrawal from others and negative social experiences.

GENDER, AGE, AND EDUCATION

The analyses described above are repeated for groups according to gender, age, and education. All psychometric analyses show the same results, with one exception. The negative

Table 7 Mean (SD) scale scores according to gender, age, and education

\begin{tabular}{|c|c|c|}
\hline & \multicolumn{2}{|c|}{ Social experiences checklist } \\
\hline & Positive & Negative \\
\hline \multicolumn{3}{|l|}{ Gender: } \\
\hline Men & $21.9(3.87)$ & $13 \cdot 1 \quad(3 \cdot 18)$ \\
\hline Women & $22 \cdot 7(3.95)$ & $12.7 \quad(3.13)$ \\
\hline \multicolumn{3}{|l|}{ Age: } \\
\hline $20-29$ & $23.4(3.77)$ & $12.8 \quad(2.96)$ \\
\hline $30-39$ & $22.5(3.85)$ & $12.9 \quad(3.07)$ \\
\hline $40-49$ & $21.9(3.96)$ & $13.1 \quad(3.30)$ \\
\hline $50-59$ & $21.7(3.94)$ & $12.7 \quad(3.21)$ \\
\hline \multicolumn{3}{|l|}{ Education: } \\
\hline & $21.6(4.01)$ & $13 \cdot 14(3 \cdot 37)$ \\
\hline Medium & $22.6(3.79)$ & $12.75(3.05)$ \\
\hline High & $23.3(3.71)$ & $12.54(2.78)$ \\
\hline
\end{tabular}

The number ranges from 33149 to 33241 .

All means are statistically different, F-test ANOVA, $p<0.001$ item 10 ("excessive concern") shows a factor loading of 0.28 or higher on both factors only for people aged 40 years or older. Among younger people this item only loads on the negative factor, as expected.

Mean scores per group are presented in table 7. Women and highly educated people seem to have more positive and fewer negative social experiences than men and people with lower education. Younger people have more positive social experiences than older people. For negative experiences the relationship with age is less clear. The amount of negative experiences increases gradually in the age group of 20-29 years to the group of 40 to 49 years of age. The oldest people in the study, those aged 50 to 59 report fewer negative social experiences than any other age group.

\section{Discussion}

This study aimed to examine the psychometric qualities of an instrument to measure positive and negative social experiences (developed in a clinical setting) in a general population. The reliability of the positive and negative SEC can be considered reasonably good. The four theoretically distinguished dimensions of support - "emotional", "affirmational", "presence", and "instrumental" - could not be distinguished. This may be because these dimensions are wrongly considered to be mutually independent and can not therefore be expressed in four factors by the method used.

These results confirm earlier findings regarding the independence of positive and negative experiences and the validity of the instrument. ${ }^{18}$ It seems that the SEC can be used in a broader perspective than the patient population it was originally developed for (cancer patients). Tempelaar et al. ${ }^{1819}$ studied the psychometric qualities of the SEC within the scope of a study on the quality of life of cancer patients. The population in that study was heterogeneous: 217 cancer patients under treatment, 192 "disease free" patients, and a sample of 201 respondents from a general population. The most important findings were that the answers on the positive items were well distributed and that the answers on the negative items were skewed to the left. The positive and negative experiences were independent, but the four described dimensions could not be distinguished within the positive and negative domain. The reliability of both the positive and negative experiences checklist was good, and the validity of the instrument was satisfactory. The fact that in our study we asked about social experiences during the last month instead of the last week had no consequences for the reliability, the structure, or the validity of the checklist compared with the results of Tempelaar et al. ${ }^{18}$

Results with regard to scores according to gender, age, and education differ somewhat from those reported by Tempelaar et al. ${ }^{19}$ Their results (for surgical patients only) concerning the relationship with age are similar to ours: younger people have more positive social experiences than older people, and the oldest 
people report fewer negative social experiences than any other age group. In our study, women and highly educated people appear to have more positive and fewer negative social experiences than men and people with lower education. Tempelaar et $a l^{19}$ did not find any differences with regard to education. In their study, women reported more positive and more negative social experiences. Unfortunately, they did not report mean scores for the respondents from the general population incorporated in their study. Therefore, it is not possible to determine the cause of these differences.

Some observations can be made. In the first place, the distribution of the answers on both the positive and negative checklists is less skewed than in the earlier research on cancer patients. ${ }^{18}$ This can be explained by the fact that our research was carried out within a general population. In a small scale study on the quality of life of cancer patients it was shown that a general population has fewer extreme scores on both dimensions than a group of cancer patients. ${ }^{33}$ The fact that the distribution of the negative checklist was more skewed to the left than the positive list, is confirmed by findings of other studies.$^{34}$ It is not clear whether this finding reflects a tendency to under-report negative experiences, or a low frequency of negative compared with positive social experiences. Secondly, the answers on the item "excessive concern" (item 10) diverge from the general pattern. Contrary to the other negative items, "excessive concern" is also related to the items measuring positive experiences. "Excessive concern" has both a positive and a negative emotional value, in particular for older people. Tempelaar et $a l,{ }^{19}$ who reported similar findings in cancer patients, suggested the removal of the item on "excessive concern" from the checklist in future research. They proposed to add a new item ("did you experience in your contacts with other people during the previous week that they let you down"). This item is supposed to reflect presence in a negative way. Thirdly, the overall response rate is rather low in our study. Despite this fact, we were able to collect data on a very large number of respondents. Since this number is so large (also within sub-categories of gender, age, and education), we do not expect that our results will be biased because of selective non-response. Furthermore, the number of respondents who did not answer all the items on social experiences is a little over $10 \%$. This number is quite low considering the number of items that the scale includes (16).

Finally, we want to discuss matters related to the validity of our scale. One way to determine construct-validity of a scale is to test the relationship between the scale and other concepts, according to theoretically or empirically derived expectations. Based on previous research $^{19}$ we expected a negative correlation of neuroticism with positive social experiences, and a positive correlation with negative social experiences. Positive social experiences were also expected to relate to active coping. ${ }^{31}$ In our data, these relationships were confirmed. For further validation of the SEC, we suggest a study of social experiences in relation to other concepts in the field of characteristics of social contacts as described by Schwarzer and Leppin. ${ }^{7}$ Unfortunately, we have no data available on these concepts (behavioural support, type-, quantity- and structure of social contacts).

Although a number of scales on social support in the English language existed by the time The Netherlands monitoring project on cardiovascular disease risk factors started, ${ }^{35}$ there was no valid Dutch scale available. It was therefore questionable whether it would be possible to use the SEC for this purpose in a general population, since this scale was only used and validated in The Netherlands in research on cancer patients. ${ }^{1819}$ Our results showed that this instrument, originally developed for cancer patient studies, is useful within a general population as well. Whether social experiences are a predictor for incidence or survival of cardiovascular and other (chronic) diseases has to be established in the future.

1 Leavy RL. Social support and psychological disorder: a review. Fournal of Community Psychology 1983;11:3-21.

2 Wallston BS, Alagna SW, DeVellis BM, DeVellis RF. Reviews. Social support and physical health. Health Psychol $1983 ; 2: 367-91$

3 Wortman CB, Conway TL. The role of social support in adaptation and recovery from physical illness. In: Cohen S, Syme SL eds. Social support and health. New York: S, Syme SL eds. Social support

4 Ganster DC, Victor B. The impact of social support on mental and physical health. Br f Med Psychol 1988;61: mental $17-36$.

5 Cohen S. Psychosocial models of the role of social support in the etiology of physical disease. Health Psychol 1988;7: 269-97.

6 Cohen S. Social supports and physical health: symptoms, health behaviours, and infectious disease. In: Cummings M, Greene AL, Karraker KH. Life-span developmental psychology: perspective on stress and coping. Hillsdale/New York: Lawrence Erlbaum, 1989,213-34.

7 Schwarzer R, Leppin A. Social support and health: a theoretical and empirical overview. Fournal of Social and Personal Relationships 1991;8:99-127.

8 Wortman CB. Social support and the cancer patient. Cancer 1984;10:2239-60.

9 House JS, Umberson D, Landis KR. Structures and processes of social support. Annual Revues in Sociology 1988; 14:293-18

10 Cohen S, Wills TA. Stress, social support, and the buffering hypothesis. Psychol Bull 1985;98:310-57.

11 Cassel J. An epidemiological perspective of psychosocial factors in disease etiology. Am $\mathcal{F}$ Public Health 1974;64: $1040-43$.

12 Cassel J. The contribution of the social environment to host resistance. Am 7 Epidemiol 1976;104:107-23.

13 Caplan G. Support systems and community mental health. Lectures on concept development. New York: Behavioral Publications, 1974

14 Cobb S. Social support as a moderator of life stress. Psychosom Med 1976;38:300-14

15 Welin L, I arsson B, Svardsudd K, Tibblin B, Tibblin G. Social network and activities in relation to mortality from Social network and activities in relation to mortality from
cardiovascular diseases, cancer and other causes: a 12 year cardiovascular diseases, cancer and other causes: a 12 year
follow up of the study of men born in 1913 and 1923.7 follow up of the study of men born in 1913 and
Epidemiol Community Health 1992;46:127-32.

16 Olsen O. Impact of social network on cardiovascular mortality in middle aged Danish men. $\mathcal{f}$ Epidemiol Community Health 1993;47:176-80.

17 Shumaker SA, Czajkowski SM. Social support and cardiovascular disease. New York/London: Plenum Press, 1994.

18 Tempelaar R, Haes JCJM de, Heuvel WJA van den, Nieuwenhuijzen MG van, Pennink BJW. Een meetinstrument voor positieve en negatieve ervaringen van (kanker-)patiënten. Tijdschrift voor Sociale Gezondheidszorg 1987;65:648-53.

19 Tempelaar R, Haes JCJM de, Ruiter JH de, Bakker D, Heuvel WJA van den, Nieuwenhuijzen MG van. The social experiences of cancer patients under treatment: a social experiences of cancer patients under treatm
comparative study. Soc Sci Med 1989;29:635-42.

20 Thoits PA. Conceptual, methodological and theoretical problems in studying social support as a buffer against ife stress. F Health Soc Behav 1982;23:145-59.

21 Vliert $\mathrm{E}$ van de, Boer $\mathrm{F}$ de. Sociale steun als determinant van gezondheid: suggesties voor verder onderzoek. Gezondheid en Samenleving 1984;1:2-8.

22 Bloom R. Social support systems and cancer: a conceptual view. In: Cohen J, Cullen JW, Martin LR eds. Psychosocial aspects of cancer. New York: Raven Press, 1982, 129-49. 
23 Pearlin LI. Social structure and social support processes In: Cohen S, Syme L eds. Social support and health. New York: Academic Press, 1985,43-60.

24 Hobfoll SE, Parris Stephens MA. Social support during extreme stress: consequences and intervention. In: Sarason extreme stress: consequences and intervention. In: Sarason BR, Sarason IG, Pierce GR eds. Social support. An in teractional view. New York: Wiley \& Sons, 1990,454-81.

25 Coyne JC, Ellard JH, Smith DAF. Social support, interdependence, and the dilemmas of helping. In: Sarason BR, Sarason IG, Pierce GR eds. Social support. An interactional view. New York: Wiley \& Sons, 1990,129-49.

26 Fiore J, Becker J, Coppel DB. Social network interactions: a buffer or a stress? Am $\mathcal{F}$ Community Psychol 1983;11: 423-39.

27 Pagel MD, Erdly WW, Becker J. Social networks: we get by with (and in spite of) a little help from our friends. $\mathcal{f}$ Pers Soc Psychol 1987;53:793-804.

28 Schuster T, Kessler R. Positive interactions, negative interactions and depressed mood. Am $\mathcal{F}$ Community Psychol 1990;18:423-38.

29 Revenson TA, Wollmann CA, Felton BJ. Social support as stress buffers for adult cancer patients. Psychosom Med stress buffers for

30 Ormel J. Moeite met leven of een moeilijk leven. Groningen: Uitgeverij Konstapel, 1980.

31 Heller K, Swindle RW. Social networks, perceived social support, and coping with stress. In: Felner RD, Jason LA, Moritsugu J, Farber SS eds. Prevention psychology: theory research and practice in community intervention. New York Pergamon Press, 1983,87-103.

32 Ormel J. Neuroticism and well-being inventories: measuring traits or states? Psychol Med 1983;13:165-76.

33 Haes JCJM de. Kwaliteit van leven van kankerpatiënten. Lisse: Swets \& Zeitlinger, 1988. Revenson TA, Schiaffino KM Majerovitz SD, Gibofsky A. Social support as a doubleedged sword: the relation of positive and problematic support to depression among rheumatoid arthritis patients. Soc Sci Med 1991:33:807-13.

35 Orth-Gomér K, Uden A-L. The measurement of social support in population surveys. Soc Sci Med 1987;24:83-94.

\section{Appendix}

THE SOCIAL EXPERIENCES CHECKLIST IN THE QUESTIONNAIRE OF THE NETHERLANDS MONITORING PROJECT ON CARDIOVASCULAR DISEASE RISK FACTORS

We will now ask you some questions about your contacts with other people. Can you give an indication how often you experienced certain reactions during the previous month?

Did you experience in your contacts with other people during the previous month:

\begin{tabular}{llllll}
\hline Warmth and friendliness & never & sometimes & regularly & often & missing \\
\hline Incomprehension & never & sometimes & regularly & often & missing \\
\hline Esteem & never & sometimes & regularly & often & missing \\
\hline That people were not willing to help you & never & sometimes & regularly & often & missing \\
\hline That someone spent a pleasant time with you & never & sometimes & regularly & often & missing \\
\hline That someone belittled you & never & sometimes & regularly & often & missing \\
\hline That people did not give you enough information & never & sometimes & regularly & often & missing \\
\hline Understanding and sympathy & never & sometimes & regularly & often & missing \\
\hline Useful information or suggestions & never & sometimes & regularly & often & missing \\
\hline Excessive concern & never & sometimes & regularly & often & missing \\
\hline That someone avoided you & never & sometimes & regularly & often & missing \\
\hline The help of someone & never & sometimes & regularly & often & missing \\
\hline That someone did not take you seriously & never & sometimes & regularly & often & missing \\
\hline That people did not leave you in peace & never & sometimes & regularly & often & missing \\
\hline That someone trusted you & never & sometimes & regularly & often & missing \\
\hline That someone took time to be with you & never & sometimes & regularly & often & missing \\
\hline
\end{tabular}

